\title{
O papel da família e de organizações civis \\ no ensino de português para crianças brasileiras
}

\author{
Ana Beatriz Barboza de Souza*
}

A emigração brasileira se tornou significativa nos anos 1980 e tem se espalhado por todos os continentes. Este fenômeno é retratado por trabalhos acadêmicos nos Estados Unidos da América (cf. JOUËT-PASTRÉ e BRAGA, 2008), que hoje é considerado o país com o maior número de brasileiros. ${ }^{1} \mathrm{O}$ Japão é o segundo país com grande concentração de brasileiros, e a Inglaterra agora desponta como o país europeu com maior crescimento no fluxo de imigrantes brasileiros.

Corrêa Costa (2007, p.102) acredita que os Estados Unidos e os países europeus, devido a suas longas experiências com processos migratórios, estejam melhor preparados que o Japão para receber alunos estrangeiros em suas redes de ensino público. Porém, como demonstrado por Mota (2002) em seu estudo sobre as políticas de educação bilíngue nos Estados Unidos, a maneira como os estrangeiros são recebidos não é necessariamente positiva. A adoção de um bilinguismo transitório leva a situações de competitividade linguística em que o uso do português está em desvantagem, apesar dos esforços das famílias brasileiras em promoverem o uso desta língua entre seus filhos (MOTA, 2004). O sucesso dos Estados Unidos em incorporar os estrangeiros em seu sistema educacional, ao qual Corrêa Costa (2007) se refere, resulta da oferta de cursos de inglês (ESOL - English for Speakers of Other Languages) aos imigrantes

\footnotetext{
* Pós-doutoranda na Universidade de Londres (Goldsmiths), onde desenvolve um projeto sobre Lingua, Identidade e Religião com imigrantes brasileiros; co-fundadora da ABRIR - Associação Brasileira de Iniciativas Educacionais no Reino Unido e integrante do Grupo de Estudos sobre Brasileiros no Reino Unido - GEB.
} 
recém-chegados. Esses cursos também são oferecidos pelo Governo Britânico, porém, na prática, não estão ao alcance de todos os imigrantes, como explicado abaixo.

O caso das crianças de famílias imigrantes é diferente. Ao invés de serem matriculadas em cursos de inglês que as preparem para acompanhar as atividades escolares, elas se juntam às crianças locais no sistema educacional regular, no qual recebem apoio educacional, como detalhado abaixo. Porém, essa política educacional visa à integração da criança na sociedade inglesa e tende a criar uma situação de bilinguismo subtrativo, em que a língua do país onde os imigrantes se estabelecem é considerada mais importante e pode levar ao desaparecimento de suas línguas maternas. Assim, pretendo neste texto discutir a resposta de pesquisadores a este sistema em geral e enfocar o desenvolvimento de diretrizes educacionais que tentam apoiar o bilinguismo aditivo de crianças de famílias imigrantes no Reino Unido, fazendo com que tanto a língua local (inglês) como a dos vários grupos minoritários sejam valorizadas. Adiciono a esta discussão um retrato da atuação de famílias brasileiras em Londres em prol do ensino de português para seus filhos e de organizações voluntárias brasileiras e concluo com sugestões de como esta atuação pode se desenvolver de uma maneira mais efetiva.

\section{Adultos imigrantes no Sistema Educacional Inglês}

O Sistema Educacional Inglês oferece cursos de ESOL (Inglês como Segunda Língua) para imigrantes através dos "Further Education Colleges", também chamados de "Community Colleges". Estas instituições oferecem cursos para alunos a partir dos 16 anos que estejam interessados em ingressar em universidades, assim como cursos técnicos e vocacionais. Os cursos de ESOL não só ensinam a falar a língua local, mas também cobrem os costumes e as leis locais e, assim, ajudam na adaptação dos imigrantes ao modo de vida no Reino Unido.

Até o ano acadêmico de 2006/2007, esses cursos eram totalmente subsidiados pelo Governo Britânico. Porém, a partir do ano seguinte, apenas os alunos desempregados ou em recebimento de benefícios específicos podem estudar gratuitamente, apesar de terem de pagar uma taxa administrativa para se matricular. $O$ direito ao estudo gratuito se aplica a refugiados, asilados políticos, e portadores de passaporte de países que fazem parte da União Europeia com residência de pelo menos três anos em um desses países. Em outras palavras, muitos dos brasileiros não se encaixam neste perfil e se matriculam em cursos de EFL (Inglês como Língua Estrangeira), os quais não recebem nenhum subsídio governamental. Já no caso dos brasileiros em situação imigratória irregular, a opção é frequentar cursos de inglês organizados por grupos voluntários latinoamericanos. Além de não exigirem documentação para matrícula, estes cursos são muitas vezes gratuitos. 


\section{Crianças (de famílias de) imigrantes no Sistema Educacional Inglês}

É importante também lembrar que os cursos de ESOL são voltados ao ensino de adultos, e portanto não apropriados para crianças, as quais devem ser matriculadas no sistema educacional inglês de acordo com suas idades. A educação em tempo integral é compulsória para todas as crianças entre os 5 e 16 anos de idade que residam no Reino Unido, independente do seu status imigratório. Apesar desta informação ser veiculada pelo próprio "Home Office" (que envolve o Departamento de Imigração britânico) ${ }^{2}$, as escolas tendem a pedir o passaporte dos pais como comprovante de identidade para efetivação de matrícula. Este procedimento leva algumas famílias em situação imigratória irregular a recearem denúncias ao Departamento de Imigração e, consequentemente, mantêm seus filhos fora da escola, retardam a matrícula de seus filhos e/ou se envolvem em falsificação de documentos. De qualquer maneira, sendo compulsória, a educação para crianças entre 5 e 16 anos é oferecida gratuitamente pelo Estado, apesar de também existirem escolas particulares. Em ambos os casos, as crianças recém-chegadas são matriculadas em anos escolares que correspondam as suas faixas etárias.

Em caso de crianças recém-chegadas que não falam inglês, um apoio educacional thes é oferecido através do serviço de professoras assistentes que os acompanham nas aulas. As assistentes podem prestar assistência a uma única criança ou a um pequeno grupo através da simplificação das instruções dos professores e do uso de gestos, entre outras maneiras. Algumas vezes essas assistentes são bilíngues e também ajudam as crianças através do uso de tradução/interpretação. Outras vezes, as crianças recebem tarefas diferenciadas das que já dominam o inglês, o que pode acontecer dentro da sala de aula ou em sala separada. É possível encontrar casos em que as crianças que possuem inglês como língua adicional tenham aulas de inglês e/ou matemática separadamente de suas turmas, e às vezes, junto com crianças consideradas portadoras de necessidades especiais. Porém, essa política educacional visa a integração da criança na sociedade inglesa e tende a criar uma situação de bilinguismo subtrativo. Em outras palavras, o uso da língua materna nas escolas inglesas tende a ser temporário e com o intuito de integrar as crianças à sociedade inglesa com uma visão assimilacionista, em que existe uma expectativa de que os grupos minoritários devam abrir mão de suas culturas a favor da cultura local (BAKER, 2007, p. 400). Apesar disso, a importância das línguas e culturas comunitárias é reconhecida não só por pesquisadores na Inglaterra, mas também em vários outros países e tem se refletido nas diretrizes educacionais inglesas.

\section{Diretrizes educacionais na Inglaterra}

Conteh et al. (2007, p. 2-9) apresentam uma visão geral de como as diretrizes educacionais na Inglaterra se desenvolveram em relação às mudanças 
em sua população desde a Segunda Guerra Mundial. O primeiro relatório que reconheceu o impacto da chegada de pessoas das ex-colônias britânicas no sistema educacional foi escrito no início dos anos 1960, período em que se adotava uma perspectiva assimilacionista, na qual as crianças eram retiradas de suas salas de aula para terem aulas de inglês. Já a perspectiva educacional adotada nos anos 1970 era multiculturalista e defendia que as crianças de imigrantes deveriam ser ensinadas junto com as outras crianças ao longo das outras matérias. Durante os anos 1980, os estudos sobre as várias línguas sendo usadas pelos imigrantes continuaram e as diretrizes educacionais publicadas através do "Swann Report" (1985, in: CONTEH et al., 2007) refletiam a recomendação de que o ensino dessas línguas deveria ser feito pelas suas próprias comunidades.

Acredita-se que esta recomendação tenha levado à total separação das línguas comunitárias do ensino regular. Porém, esta recomendação resultou de consultoria com algumas orgarnizações civis, receosas de que o financiamento e a intervenção governamental pudessem levar a limitações do trabalho oferecido pelas diversas iniciativas comunitárias com seus diversos objetivos e focos (BOURNE, 2007, p. 135-137).

Os anos 1990 testemunharam a implementação de um currículo nacional que re-introduziu uma perspectiva assimilacionista com foco em gramática do ponto de vista de um falante monolíngue de inglês e, com total desconsideração da situação das crianças que aprendiam inglês como língua adicional, os "EAL learners". Esse currículo, porém, foi revisado para incluir as necessidades de crianças que não possuem inglês como primeira língua e atualmente oferece mensagens positivas em relação às conexões entre o aprendizado que se dá nas escolas regulares e nas escolas comunitárias (cf. DFES, 2006).

As novas diretrizes adotadas para o programa de escola primária (DFES, 2006) refletem o modelo de apoderamento de Cummins (1986, p. 21), o qual defende que as relações entre educadores e alunos "imigrantes" e entre as escolas e as comunidades minoritárias precisam ser mudadas para a promoção do sucesso escolar dessas crianças, e assim, entre outras coisas, encoraja a participação da comunidade minoritária na educação da criança.

A importância da participação dos pais e das organizações comunitárias no aprendizado das crianças também foi ressaltado por Faltis (1995), que nos chama a atenção para as vantagens dos pais, neste caso ingleses - em relação aos pais brasileiros - por falarem inglês, a língua oficial usada na escola, e pelo grau de envolvimento que mantêm com as escolas através da participação em atividades extracurriculares, do envolvimento em atividades organizadas pela associação de pais e mestres e da possibilidade de estudarem com seus filhos em casa, por exemplo.

Faltis (1995, p. 247) também ressalta a necessidade de pais imigrantes obterem informações sobre como acessar o sistema, como exercer influências na educação de seus filhos e entender quais os eventos relevantes para sua participação. Assim, Faltis enfatiza a importância da cooperação entre escola, 
professores e pais e propõe um modelo de interação entre escola e família que se inicia com o professor obtendo informações sobre os pais e suas comunidades e termina com a contribuição ativa dos pais em decisões curriculares.

Este modelo tem sido aplicado em algumas escolas inglesas e Sneddon (1997) relata as mudanças que vêm ocorrendo no relacionamento escola-família na Inglaterra desde os anos 1960. Como exemplos, Sneddon (1997, p. 145) cita especificamente o envio regular de cartas aos pais, a existência de associações de pais e mestres assim como a organização de eventos socias e reuniões em que os métodos de ensino são explicados, além de convidarem os pais para participarem como voluntários de eventos curriculares e extracurriculares.

Sneddon (1997, p. 152) também constata a existência de um grande número de organizações civis, "community organizations", criadas pelos diferentes grupos de imigrantes e reconhece a sua importância pelo apoio oferecido a suas comunidades em relação a aspectos culturais, linguísticos, religiosos e migratórios.

\section{Organizações civis}

Atualmente, é possível encontrar várias organizações brasileiras (e latinoamericanas) que atuam em áreas diversas em apoio aos imigrantes que vivem no Reino Unido. Esse apoio inclui associações que prestam assistência em relação a assuntos migratórios em geral, tais como ABRAS (Associação Brasileira no Reino Unido), ${ }^{3}$ assim como assuntos mais específicos, por exemplo, saúde sexual (Naz Vidas), ${ }^{4}$ portadores de deficiências (LADPP) ${ }^{5}$ e casos de violência doméstica (LAWRS). ${ }^{6}$ Além disso, existem associações com um foco cultural e educacional tais como a Brazil in Wales, no país de Gales; a Brasil Caledônia, na Escócia; e o Viva Brasil,? na Inglaterra.

Com um foco especificamente educacional, mas que abrange todo o Reino Unido, a ABRIR (Associação Brasileira de Iniciativas Educacionais no Reino Unido) ${ }^{8}$ foi fundada em 2006 com o apoio do Consulado-Geral do Brasil em Londres através da figura do então Cônsul, Embaixador Flávio Perri. Desde então, esta associação tem apoiado a formação de novos grupos de pais brasileiros que visam a ensinar português para seus filhos, assim como tem apoiado outros grupos no desenvolvimento de seus projetos educacionais. A ABRIR oferece orientação sobre seleção, contratação, treinamento e qualificação para professores brasileiros; sobre o desenvolvimento de currículo para o ensino de Português como língua estrangeira e materna, assim como de currículo para o ensino de inglês para brasileiros; sobre material didático e paradidático; sobre a criação e desenvolvimento de redes de contato com outros grupos no Reino Unido e no exterior; e sobre a obtenção e o uso de recursos humanos e financeiros.

A ABRIR também tem sido representada nos fóruns de brasileiros no exterior, tais como o I Seminário das Comunidades Brasileiras no Exterior, em 2008, no Rio de Janeiro, e o III Encontro da Rede de Brasileiros e Brasileiras na Europa, sediado na Espanha em 2009, visando a chamar a atenção para as 
dificuldades vivenciadas pelas famílias brasileiras no exterior em relação aos assuntos relacionados ao bilinguismo e à educação das crianças dessas famílias, assim como tentar encontrar soluções práticas que possam ser úteis tanto às famílias quanto às escolas.

\section{Escolas de línguas comunitárias}

Escolas de línguas comunitárias, as "community language schools" (também chamadas escolas suplementares ou complementares), são escolas criadas por grupos de imigrantes devido a suas necessidades de preservar suas heranças culturais e linguísticas no país para o qual imigraram (SNEDDON, 1997, p. 153).

Li Wei (2006) refere-se a três fases no surgimento de escolas comunitárias no Reino Unido. As primeiras escolas comunitárias surgiram no final dos anos 1960 e foram direcionadas a crianças de famílias Afro-Caribenhas com ênfase em aspectos culturais específicos deste grupo. No final dos anos 1970 e início dos anos 1980 surgiram as escolas comunitárias direcionadas às famílias muçulmanas da Ásia e da África, cuja ênfase era em suas tradições religiosas. Na mesma época, um grande número de outras comunidades abriram escolas com foco em suas heranças linguísticas e culturais.

Como mencionado acima, foi nos anos 1980 que a imigração brasileira para o Reino Unido se intensificou e, desde então, famílias de diferentes níveis educacionais e econômicos têm se unido devido a importância que dão à Língua Portuguesa na construção de suas identidades como brasileiros, e assim, têm feito esforços para manter o uso de português entre seus filhos (SOUZA, 2008).

A primeira escola comunitária brasileira de que se tem registro foi formada em 1997. BrEACC (Brazilian Educational and Cultural Centre), o Centro Brasileiro de Educação e Cultura, foi fundado por um grupo de mães que queria que seus filhos aprendessem português e ao mesmo tempo se socializassem com outras crianças "brasileiras". ${ }^{9}$ O número de grupos comunitários brasileiros com foco no ensino de português para crianças muda constantemente (SOUZA, 2010b). Além do BrEACC, quatro outras escolas já existiram: o BCA - Brazilian Contemporary Arts, O Visconde, Escola Brasileira de Bromley, e Escola Portuguesa Suplementar ("Portuguese Supplementary School").

Essas escolas foram criadas em áreas diferentes de Londres e não funcionaram necessariamente durante o mesmo período. $O$ dia e a duração das aulas, assim como o método de ensino, eram variados nas diversas escolas, porém todas fecharam por falta de recursos humanos e/ou financeiros. Entretanto, essas quatro escolas e os outros grupos de pais que atualmente funcionam informalmente (cf. rede de contatos da ABRIR) indicam que as famílias brasileiras gostariam que seus filhos aprendessem português. Este desejo pode estar vinculado ao fato de algumas famílias considerarem essencial a ligação entre língua e identidade, como ilustrado por mães participantes do meu estudo de doutorado (cf. SOUZA, 2010a) e exemplificado abaixo: 
Mãe 1. Eu sou brasileira, eu não nasci aqui. Minha cultura é brasileira, então, português é importante para que meus filhos entendam tudo isto.

Mãe 2. Português é minha língua, e meus filhos são metade brasileiros. Então, eu acho horrível quando alguém diz 'Minha mãe é brasileira', mas eles não conseguem falar uma palavra em português.

Mãe 3. Você não é brasileiro se não fala português... Não faz sentido a mãe falar português e os filhos não...

A ligação dessas mães com o Brasil resulta de suas necessidades emocionais de estar em contato com suas "raízes" linguísticas e culturais (SOUZA, 2008). Porém, a Escola Portuguesa Suplementar era aberta a todos os falantes de língua portuguesa. Independente de enfocar em nacionalidades específicas ou não, acredita-se que frequentar aulas em escolas comunitárias pode melhorar o desenvolvimento escolar das crianças, como o caso comprovado dos alunos de origem afro-caribenha estudados por Tikly et al. (DFES, 2002, In: CONTEH et al., 2007, p. 11). No caso do grupo de crianças brasileiras que estudei (SOUZA, 2010b), a escola comunitária é o principal local onde as crianças interagem entre si em português, tendo assim uma importante função na preservação da Língua Portuguesa entre as crianças de famílias brasileiras crescendo em Londres.

Outras organizações comunitárias com um importante papel na preservação de línguas são os grupos religiosos (FRESTON, 2008, p. 258), pois tanto as igrejas católicas e evangélicas, assim como grupos kardecistas utilizam o idioma português antes, durante e depois das cerimônias religiosas (SOUZA, 2009). 0 impacto dos grupos religiosos - mais especificamente das aulas de catequese, de ensino religioso e de evangelização - no uso do português e na construção de uma identidade brasileira pelas crianças de famílias brasileiras vem crescendo em Londres. $\mathrm{O}$ impacto desses grupos ainda está por ser analisado, no entanto, o papel desses grupos comunitários na promoção dos interesses dos grupos de língua minoritária e na preservação de suas línguas não pode ser ignorado (FISHMAN, apud SNEDDON, 1997, p. 153).

\section{Conclusão}

A absorção de crianças de famílias de imigrantes no sistema educacional inglês não é necessariamente vantajosa para o desenvolvimento de suas identidades e muito menos para o desenvolvimento de suas habilidades linguísticas. Apesar das mudanças nas diretrizes educacionais discutidas acima, "na melhor das hipotéses, as escolas regulares negligenciam, e na pior das hipóteses, elas negam [a essas crianças o direito à] diversidade linguística e cultural" (HALL et al., apud CONTEH et al., 2007, p. 10). 
Consequentemente, é possível testemunhar um movimento das famílias brasileiras na Inglaterra em favor da preservação do uso de Português, o qual pode ser apoiado por organizações comunitárias. Estas organizações podem ter um papel importante em fazer com que as escolas regulares entendam os vários grupos de imigrantes aos quais seus alunos pertencem, reconheçam a importância da manutenção de suas línguas para os diversos grupos e possam desenvolver uma parceria adequada com elas (SNEDDON, 1997, p. 154).

Desta maneira, o trabalho feito pela ABRIR em relação ao apoio dado às famílias brasileiras para que entendam o sistema educacional inglês e para que tomem conhecimento dos recursos disponíveis para que assegurem uma posição como 'agentes' (CUMMINS, 1996, p. 4) na educação de seus filhos precisa ser revisto. É preciso estabelecer uma rede de parceria pais-escola-comunidade, como sugerido por Faltis (1995) e discutido neste artigo.

Além de apoiar as famílias brasileiras, a ABRIR precisa desenvolver um trabalho que envolva as escolas britânicas não apenas em relação a identificar e quantificar o número de crianças de famílias brasileiras no sistema educacional inglês, mas também em relação a entender suas necessidades culturais e linguísticas. Esta parceria pais-escola-comunidade também precisa envolver as autoridades brasileiras que se encontram no Brasil, no Reino Unido e em outros países onde há presença de imigrantes brasileiros.

É de suma importância considerar as diferentes formas de apoio prestadas pelo governo brasileiro à educação de crianças, jovens e adultos brasileiros nos diversos países. É necessário criar um meio de comunicação através do qual o intercâmbio de experiência e conhecimento adquiridos pelas organizações comunitárias e pelas representações brasileiras nos diversos países seja possível. Mais importante ainda é criar um mecanismo que garanta apoios concretos por parte das autoridades brasileiras em relação ao ensino da Língua Portuguesa para os filhos de brasileiros no exterior. Assim, a Língua Portuguesa poderá ser vista como um recurso que pode levar a benefícios culturais e econômicos, em vista da manutenção da diversidade linguística e cultural (BAKER, 2007, p. 419).

\section{Notas}

1 - IBGE www.ibge.gov.br/home/estatistica/populacao/censo2000/atlas/pag021.pdf. Acesso em: 17 de agosto de 2009.

2 - www.ukba.homeoffice.gov.uk/newcomerstotheuk/education. Acesso em: 18 de agosto de 2009.

3 - www.abras.org.uk

4 - www.naz.org.uk/vidas/vidasintro.html

5 - http://ladpp.org.uk/index.php?lang=pt

6 - www.lawrs.org.uk/index_por.htm

7 - www.vivabrasil.org.uk/index.php

8 - www.abrir.org.uk

9 - É importante notar que essas crianças tendem a se descrever como inglesas por terem nascido na Inglaterra, apesar de reconhecerem as outras línguas que falam e as experiências culturais a que são expostas por seus pais (SOUZA, 2007). 


\section{Referências}

BAKER, C. Foundations of Bilingual Education and Bilingualism. Clevedon: Multilingual Matters, 2007.

BOURNE, J. Reflections and Suggestions for Ways Forward. In: CONTEH, Jean et al. (orgs.) Multilingual Learning: stories form schools and communities in Britain. Stoke-on-Trent: Trentham Books, 2007, p. 135-144.

CONTEH, J. et al. Multilingual Learning Stories from Schools and Communities in Britain: Issues and Debates. In: CONTEH, J. et al. (orgs.) Multilingual Learning: stories form schools and communities in Britain. Stoke-on-Trent: Trentham Books, 2007, p.1-22.

CORRÊA COSTA, J. De Decassegui a Emigrante. Brasília: Fundação Alexandre Gusmão, 2007.

CUMMINS, J. Empowering Minority Students: A framework for intervention. In: Harvard Educational Review, n.56(1), 1986, p. 18-36.

CUMMINS, J. Negotiating Identities: Education for Empowerment in a Diverse Society. Ontario: California Association for Bilingual Education, 1996.

DFES. Excellence and enjoyment: learning and teaching for bilingual children in the primary years. Londres: Department for Education and Skills, 2006.

FALTIS, C. Building Bridges between Parents and the School. In: BAKER, C. (org.) Bilingualism and Bilingual Education - Extending the Foundation. Clevedon: Multilingual Matters, 1995, p. 245-257.

FRESTON, P. The Religious Field among Brazilians in the United States. In: JOUËT-PASTRÉ, C. e BRAGA, L. J. (orgs.) Becoming Brazuca, Brazilian Immigration to the United States. Cambridge: Harvard University Press, 2008, p. 255-268.

JOUËT-PASTRÉ, C. e BRAGA, L. (orgs.) Becoming Brazuca, Brazilian Immigration to the United States. Cambridge: Harvard University Press, 2008.

LI, W. Complementary Schools, Past, Present and Future. In: Language and Education, n. 20(1), 2006, p. 76-83.

MOTA, K. Políticas de Educação Bilíngue na Escola e na Família: Cenários de Competitividade Linguística. Trabalho apresentado no 25o Encontro da ANPED, Caxambu, 2002.

MOTA, K. Aulas de Português fora da escola: famílias imigrantes brasileiras, esforços de preservação da língua materna. In: Cadernos CEDES. Campinas: Unicamp, n. 24(63), 2004, p. 149-163.

SNEDDON, R. Working towards partnership: parents, teachers and community organisations. In: BASTIANI, J. (org.) Home-School Work in Multicultural Settings. Londres: David Fulton, 1997, p. 145-155.

SOUZA, A. Brazilians in London: the role of religious meetings in the language and identity development of their offspring. Paper apresentado na Conferência de ACIS (Association of Contemporary Iberian Studies). Irlanda, Dublin City University. 9 de set. de 2009.

SOUZA, A. How Linguistic and Cultural Identities are affected by Migration. In: Language Issues. Londres: NATECLA, 19(1), 2008, p. 36-42.

SOUZA, A. Language and Identity in a Community Language School. In: Community Languages Bulletin, n. 20. Londres: CILT, 2007. 
SOUZA, A. Migrant Languages in a Multi-Ethnic Scenario: Brazilian Portuguese in London. In: Portuguese Studies, 26(1), 2010a, p. 79-93.

SOUZA, A. Language choices: portraits of children's identity negotiations in a Community Language School. In: LYTRA, V. e MARTIN, P. (eds.) Multilingual Spaces: Complementary Schools in Contemporary Britain. Londres: Trentham, 2010b, p. 97-107.

\title{
RESUMO
}

A emigração brasileira se tornou significativa nos anos 1980 e, na Europa, o Reino Unido desponta como um dos países com maior crescimento no número de imigrantes brasileiros. Como consequência, há um grande número de crianças brasileiras no sistema educacional inglês, além das crianças de várias outras origens. Independentemente do nível de inglês que possuem, essas crianças são matriculadas no sistema educacional regular. Neste texto, discuto as diretrizes educacionais inglesas em resposta à grande população de crianças imigrantes em suas escolas. Adiciono a esta discussão um retrato da atuação de famílias brasileiras em Londres em prol do ensino de português para seus filhos e de organizações voluntárias brasileiras. Concluo com sugestões a respeito de como a atuação destas organizações pode se desenvolver de uma maneira mais efetiva e clamo por um maior envolvimento das autoridades brasileiras na questão da educação de crianças, jovens e adultos brasileiros que vivem no exterior.

Palavras-chave: imigrantes brasileiros; educação; Reino Unido.

\begin{abstract}
Brazilian emigration became more evident in the 80 s and United Kingdom is, in Europe, one of the countries with greater increase on numbers of Brazilian migrants. As a consequence, there is a large number of Brazilian children in the British educational system, in addition to the children from many other backgrounds. Independent of their competence levels in English, these children are enrolled in mainstream schools. In this paper, I discuss the British educational policies in relation to children of immigrant families. I also present a profile of the actions taken by Brazilian families in London in favour of the teaching of Portuguese to their children as well as a profile of some of the Brazilian community organizations which are active in the UK. I conclude with suggestions on how these organizations could work more effectively and urge for more involvement from Brazilian government in relation to the education of Brazilian children and adults who live abroad.
\end{abstract}

Keywords: Brazilian immigrants; education; United Kingdom. 